\title{
Forecasting the Yield Curve with the "Stock Dog" Technique
}

\author{
Pierre Rostan ${ }^{1} \&$ Alexandra Rostan ${ }^{1}$ \\ ${ }^{1}$ American University in Cairo, New Cairo, Egypt \\ Correspondence: Pierre Rostan, Department of Management, American University in Cairo, AUC Avenue, P.O. \\ Box 74, New Cairo 11835, Egypt. Tel: 20-2-2615-3271. E-mail: prostan@aucegypt.edu
}

Received: May 12, 2012 Accepted: June 13, 2012 Online Published: August 16, 2012

doi:10.5539/ijbm.v7n16p31 URL: http://dx.doi.org/10.5539/ijbm.v7n16p31

\begin{abstract}
We design an innovative technique coupled with Monte Carlo simulation that accurately forecasts the yield curve. This "stock dog" technique forces the simulated yield curve inside bands, using the information embedded in the shapes of the most recent yield curves captured by the level, the slope and the curvature provided by the Nelson and Siegel (1987) model. Based on the RMSE criteria, we show that, on a sample of 2,321 U.S. Treasury yield curves over the 2002-2012 period, the "stock dog" technique, coupled either with the Cox, Ingersoll and Ross (1985) or a Stochastic Fifth-Order Polynomial models, is superior to the Diebold and Li (2006) model when forecasting the yield curve over a 20-day horizon. The "stock dog" technique is a variation of the Diebold and Li (2006) model and improves significantly its forecasting power. It may help market participants in need of an accurate short term forecast of the yield curve.
\end{abstract}

Keywords: yield curve forecasting, interest rate, cox, ingersoll and ross model, polynomial model, nelson and siegel model, diebold and li model, monte carlo simulation

\section{Introduction}

\subsection{Forecasting the Yield Curve}

When yields of bills and bonds are plotted against their terms, it is called the yield curve. The need to have an accurate forecast of the yield curve comes first from central banks to implement adequate monetary policy. Second, institutional investors and investment banks needs to forecast the interest-rate term structure to implement optimal investment strategies. Forecasting the term structure is crucial because the term structure is commonly considered as a 'leading indicator of the economic activity' (Zantedeschi, Damien, \& Polson, 2011). Some findings suggest that 'the spread between long-term and short-term interest rates is an excellent predictor of changes in the economic activity. Generally, when long-term interest rates have been much above short-term rates, strong increases in output have followed within about a year; however, whenever the yield curve has been inverted for any extended period of time, a recession has followed' (Clinton, 1995). Day and Lange (1997) showed 'that the slope of the nominal term structure from 1- to 5-year maturities is a reasonably good predictor of future changes in inflation over these horizons'. Finally, yield curve forecasting is essential for bond portfolio managers. Expected higher interest-rates will force them to shorten their portfolio duration and inversely.

\subsection{The "Stock Dog" Technique}

Our paper presents an innovative "stock dog" technique coupled with Monte Carlo (MC) simulation that accurately forecasts the yield curve. Similar to a pastoral dog who acts as a living fence to make sure that the herd follows the general direction, this "stock dog" technique forces the simulated interest rate inside bands that are drawn using the information embedded in the shapes of the most recent yield curves. These bands are built to reflect the intrinsic dynamic forces of the current interest rate market environment responsible of the future shape of the yield curve. One of our challenges was to identify these forces and to materialize them in bands beyond which the future yield curve is unlikely to be. Our paper will assume that the dynamic forces responsible for the shape of the yield curve can be captured by the level, the slope, and the curvature of the yield curve.

In addition, based on the efficient market theory, we assume that all available information is incorporated in the most recent yield curve; therefore we use the 1-month interest rate that we read on the yield curve today as the estimator of the 20-day forward interest rate with a zero maturity (the initial value of the simulated yield curve). Section 1.3 will review the literature concerning the forecast of the yield curve, polynomial modelling and methods that add bands to the MC simulation. Section 2 will present the three models selected in this paper and 
will introduce the "stock dog" technique. Section 3 will present the results and section 4 will wrap up our findings.

\subsection{Litterature Review}

\subsubsection{Forecasting the Yield Curve}

The theory about modelling interest-rate term structure suggests that the evolution of the yield curve shape is affected by the level of interest rates, the slope of the term structure, the curvature and the volatility of the changes: for example read Litterman and Scheinkman (1991), Chen and Scott (1993), Dai and Singleton (2000), and De Jong (2000). The term structure relates to the relationship between the interest rates that shape the yield curve. McCulloch (1971) pioneered the estimation of the term structure where coupon payments were included explicitly in a formal way. He first used quadratic splines which could be estimated by linear regression, then used cubic splines (1975). A problem with this approach, as Shea $(1984,1985)$ noted, is that the forward rate can become negative. In addition, Shea showed that the resulting yield function 'tends to bend sharply towards the end of the maturity range observed in the sample'. Vasicek (1977) proposed a mean reverting process of the short term interest rate:

$$
d r=\alpha(\mu-r) d t+\sigma d z_{t}
$$

In equation $1, \alpha$ is the speed of mean reversion, $\mu$ is the long-term average to which the short rate is reverting, and $\sigma$ is the instantaneous volatility of the short rate. All parameters are assumed constant overtime. Vasicek and Fong (1982) proposed to model the term structure using exponential splines. Cox, Ingersoll and Ross (CIR, 1985) modelled the short rate allowing the variance of the short-rate to be proportional to the level of the short rate:

$$
d r=\alpha(\mu-r) d t+\sigma \sqrt{r} d z_{t}
$$

Equations 1 and 2 are single-factor models. Since $90 \%$ of the variation in the changes of the yield curve is generally attributable to the variation in the first factor corresponding to the level of the interest rate, they are extensively used by practitioners (Rebonato, 1996). However, 'these models have a limited set of shapes. Furthermore, since all bonds are only affected by one source of uncertainty, their returns are perfectly correlated over a short period of time' (Lund \& Christiansen, 2005). 'Empirical studies have suggested that the evolution of the term structure of interest rates would be driven by the dynamics of several factors which can be represented by macroeconomic shocks or be related to the level, slope, and curvature' (Hong, 2001). To meet these empirical evidences, authors developed multifactor models such as Bliss (1997), Andersen, Lundb and Torben (1997), Dai and Singleton (2000) and Duffee (2002).

Nelson and Siegel (1987) fitted the observed yield curve with a function of the time to maturity of the fixed income securities. The model has later been modified by Svensson (1995) who estimated the forward rates mainly using the original Nelson and Siegel model but, in some cases using an extended version. Dolan (1999) argued that 'the curvature parameter of the yield curve, estimated using the Nelson and Siegel model, could be predicted using simple parsimonious models'. Fabozzi, Martellini and Priaulet (2005) tested for statistical significance in the predictive power of the Nelson and Siegel model when forecasting yield curve. Bernadell, Coche and Nyholm (2005) revisited an early version of Diebold and Li paper (2003) by adding a regime-switching expansion. Diebold and Li (2006) applied the Nelson and Siegel model to forecasting by predicting the three factors which determine the shape of the yield curve with autoregressive models. Their model was encouraging for forecasting horizons longer than 24 months. Audrino and Trojani (2007) proposed 'a multivariate nonparametric technique for generating reliable short-term historical yield curve scenarios and confidence intervals. The approach is based on a Functional Gradient Descent (FGD) estimation of the conditional mean vector and covariance matrix of a multivariate interest rate series'. Vicente and Tabak (2008) tested 'the predictive ability of a variety of models in forecasting the yield curve'. They compared affine term structure models with the Diebold and Li (2006) model. Their results suggested that forecasts made with Diebold and $\mathrm{Li}$ model 'are superior, and appear to be more accurate at long horizons than other different benchmark forecasts'. These findings confirm our sensible choice of the Diebold and Li (2006) model as a source of inspiration and as a benchmark of the "stock dog" technique. Leite, Filho and Vicente (2010) proposed 'a statistical model to forecast the yield curve, using two major sources of information: data from a market survey and the forward rate risk premium. They forecasted the yield curve six months ahead and compared the results with the Diebold and Li (2006) model, a random walk process and the predictions based on the forward rate. Their model produced accurate forecasts and outperforms all the competitor models in terms of root mean square error (RMSE)'. Füss and Nikitina (2011) dusted off the yield curve dynamics in terms of the unobservable 
components-level, slope, and curvature and applied the factor-augmented vector autoregression (FAVAR) framework for forecasting interest rates. They predicted the yield curve dynamics by directly forecasting the unobservable yield curve factors. FAVAR models with a reduced lag order showed superior short-horizon forecast performance over simple VAR systems and univariateautoregressions.

\subsubsection{Polynomial Models}

We compare the CIR (1985) and the Diebold and Li (2006) models to a stochastic fifth-order polynomial model also based on MC simulation suggested by Rostan and Rostan (2012). Several authors have proposed polynomial models to fit the yield curve. At the start of the polynomial models incubation period, pioneers like Kornbluth and Salkin (1992) discussed 'the effect of various polynomial representations of the yield curve on the tilting of medium to long term bond portfolios'. Pham (1998) proposed 'a methodology of fitting the term structure of interest rates with Chebyshev polynomials incorporated into a quantity called the interest cumulator and then subjected to a minimization procedure to yield parameters that subsequently maps out zero-coupon yield curves'. Almeida, Duarte and Fernandes (1998), 'proposed modelling the term structure of interest rates $\mathrm{R}(\bullet)$ as a linear combination of Legendre polynomials'. Bing-Huei (1999) used 'curve fitting techniques with the observed government coupon bond prices to estimate the term structure. Bing-Huei applied the B-spline functions to approximate the discount function, spot yield curve, and forward yield curve respectively'.

Bali and $\mathrm{Wu}$ (2006) provided a comprehensive analysis of the short-term interest-rate dynamics. They think of 'the drift function as a Laurent series expansion of a generic function with positive order of five and negative order of one'. They tested a fifth-order polynomial function of the interest rate. They used the fifth-order polynomial drift specification as a general nonlinear specification $\mu\left(r_{t}\right)=\alpha_{0}+\alpha_{1} r_{t}+\alpha_{2} r_{t}^{2}+\alpha_{3} r_{t}^{3}+\alpha_{4} r_{t}^{4}+\alpha_{5} r_{t}^{5}$ and contrasted it with the affine specification $\mu\left(r_{t}\right)=\alpha_{0}+\alpha_{1} r_{t}$. They concluded that 'nonlinearity exists in the very short-term interest rates process due to different speeds of mean reversion at different interest-rate levels. This difference becomes smaller for longer-maturity interest rates due to the smoothing effect of market expectations. In conclusion, it is more difficult to identify nonlinearities in the longer-term interest rates than in the very short-term ones'. In line with Bali and Wu (2006), Rostanand Rostan (2012) fitted the yield curve with a fifth-order polynomial function. In order to simulate yield curves they added an innovation term to the function as it appears in equation 18 below.

\subsubsection{Adding Bands to the Simulation}

The intuition of adding lower and upper bounds to interest rates was proposed by Delbaen and Shirakawa (2002) where the interest rate fluctuates in a bounded region. The equation of the short-term interest rate becomes:

$$
d r=\alpha\left(r_{\mu}-r_{t}\right) d_{t}+\beta \sqrt{\left(r_{t}-r_{m}\right)\left(r_{m}-r_{t}\right)} d w_{t}
$$

with $\mathrm{r}_{\mathrm{m}}<\mathrm{r}_{\mu}<\mathrm{r}_{\mathrm{M}}$.

Théoret, Rostan and El Moussadek (2005) proposed a variance reduction technique that constrains the short-term interest-rate inside Bollinger bands during the MC simulation. Rostan and Rostan (2012) proposed an innovative variance reduction technique based on a bounded distribution of the innovation term $\varepsilon$. During the $\mathrm{MC}, \varepsilon$ is drawn from a Normal distribution $\mathrm{N}(0,1)$. To speed up the convergence of the simulation, they simply reduce the interval of drawing, for instance $\varepsilon \in[-1,1]$. This is Importance Sampling since they constraint the distribution inside upper and lower bands. The intuition behind this technique is that since interest-rates are mean-reverting, the innovative term of their stochastic process should be mean-reverting to zero and behave between upper and lower bands.

\subsection{Research Design}

In the "stock dog" technique we use the intuition of building bands, beyond which the forecasted yield curve is unlikely to be. The following section will discuss this approach.

\section{Method}

We develop an innovative "stock dog" technique to forecast in 20 days the yield curve of US Treasury bills and notes of 1-month to 20-year maturity. The choice of the 20-day period (one calendar month) matches the need from Central Banks to implement adequate monetary policy within a short period of time and the need of portfolio managers to get sufficient time to unwind their positions without suffering too much slippage in case of adverse expected moves of interest rates. We benchmark our "stock dog" technique to the Diebold and Li model (2006) and to a stochastic fifth-order polynomial model. 


\subsection{Diebold and Li model (2006)}

Diebold and Li (2006) used the Nelson and Siegel model (1987). They fitted the yield curve using their three-factor model:

$$
y_{t}(\tau)=\beta_{1 t}+\beta_{2 t}\left(1-e_{t}^{-\lambda \tau}\right) /\left(\lambda_{t} \tau\right)+\beta_{3 t}\left\{\left(1-e_{t}^{-\lambda \tau}\right) /\left(\lambda_{t} \tau\right)-e_{t}^{-\lambda \tau}\right\}
$$

The inputs are:

1) The daily U.S. Treasury yield curve.

2) Fixed value of $\lambda_{t}=0.91$ for all $t$. This value is obtained from the first 250 U.S. Treasury yield curves of our database (7/31/2001 to 7/31/2002) by minimizing the average RMSE over the period, using equations 4 and 21 .

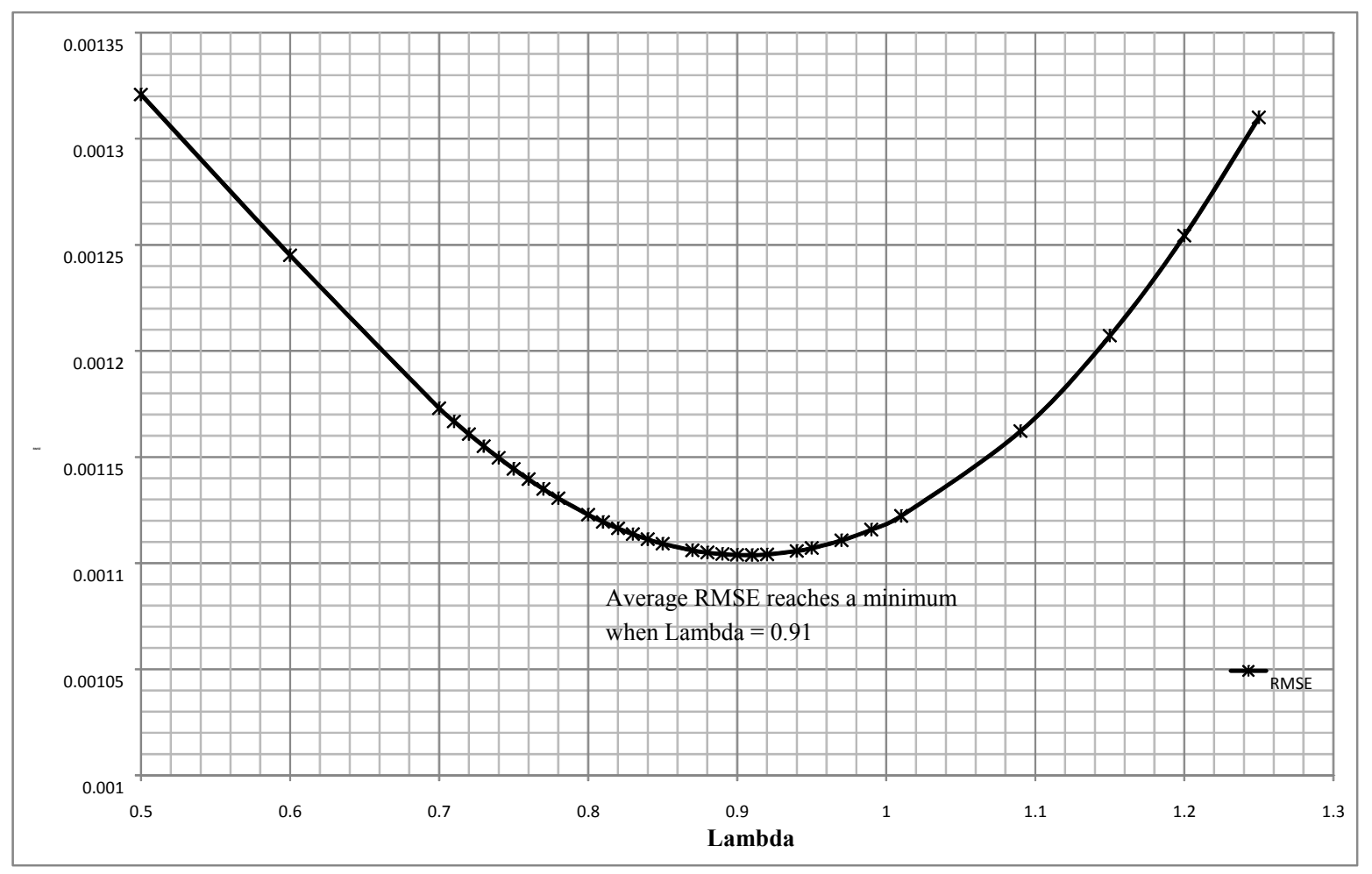

Figure 1. Setting Lambda $=0.91$ in the Nelson and Siegel (1987) model by mimimizing the average RMSE over the period from $7 / 31 / 2001$ to $7 / 31 / 2002$

Source: the authors

Figure 1 illustrates the optimal choice of lambda that minimizes the average RMSE over the 250-day period (equation 21). Nelson and Siegel applied a nonlinear least squares method to the daily observed yield curves and obtained a time series of estimates of $\left\{\beta_{1 t}, \beta_{2 t}, \beta_{3 t}\right\}$. To illustrate the fitting ability of Nelson and Siegel model (1987), figure 2 illustrates three U.S. Treasury yield curves coming from the database and fitted with Nelson and Siegel model.

We selected humped, flat and normal yield curves. We observe the limitation of the model in fitting humped yield curves. Because the yield-curve depends only on the three estimated factors $\left\{\beta_{1 t}, \beta_{2 t}, \beta_{3 t}\right\}$, forecasting the yield curve is equivalent to forecasting $\left\{\beta_{1 t}, \beta_{2 t}, \beta_{3 t}\right\}$. Therefore, Diebold and Li (2006) modelled and forecasted the Nelson and Siegel factors as univariate AR(1) process. Diebold and Li produced yield forecasts based on an underlying univariate $\operatorname{AR}(1)$ specification, as:

$$
y_{t+h / t}(\tau)=\beta_{1, t+h / t}+\beta_{2, t+h / t}\left(1-e^{-\lambda \tau}\right) /(\lambda \tau)+\beta_{3, t+h / t}\left(\left(1-e^{-\lambda \tau}\right) /(\lambda \tau)-e^{-\lambda \tau}\right)
$$

where:

$$
\beta_{i, t+h / t}=C_{i}+\omega_{i} \beta i t
$$


In our paper, the forecasting horizon is $h=20$ days. We regress the first set of $\beta_{1 t}, \beta_{2 t}, \beta_{3 t}$ from 1 to 250 days with the set of $250\left\{\beta_{l t}, \beta_{2 t}, \beta_{3 t}\right\}$ obtained between 20 and 270 days, then moving forward one-day at a time. The resulting $\left\{\beta_{1 t}, \beta_{2 t}, \beta_{3 t}\right\}$ are then plugged in equation 5 in order to compute the forecasted interest-rate in 20 days corresponding to each maturity of the term structure.

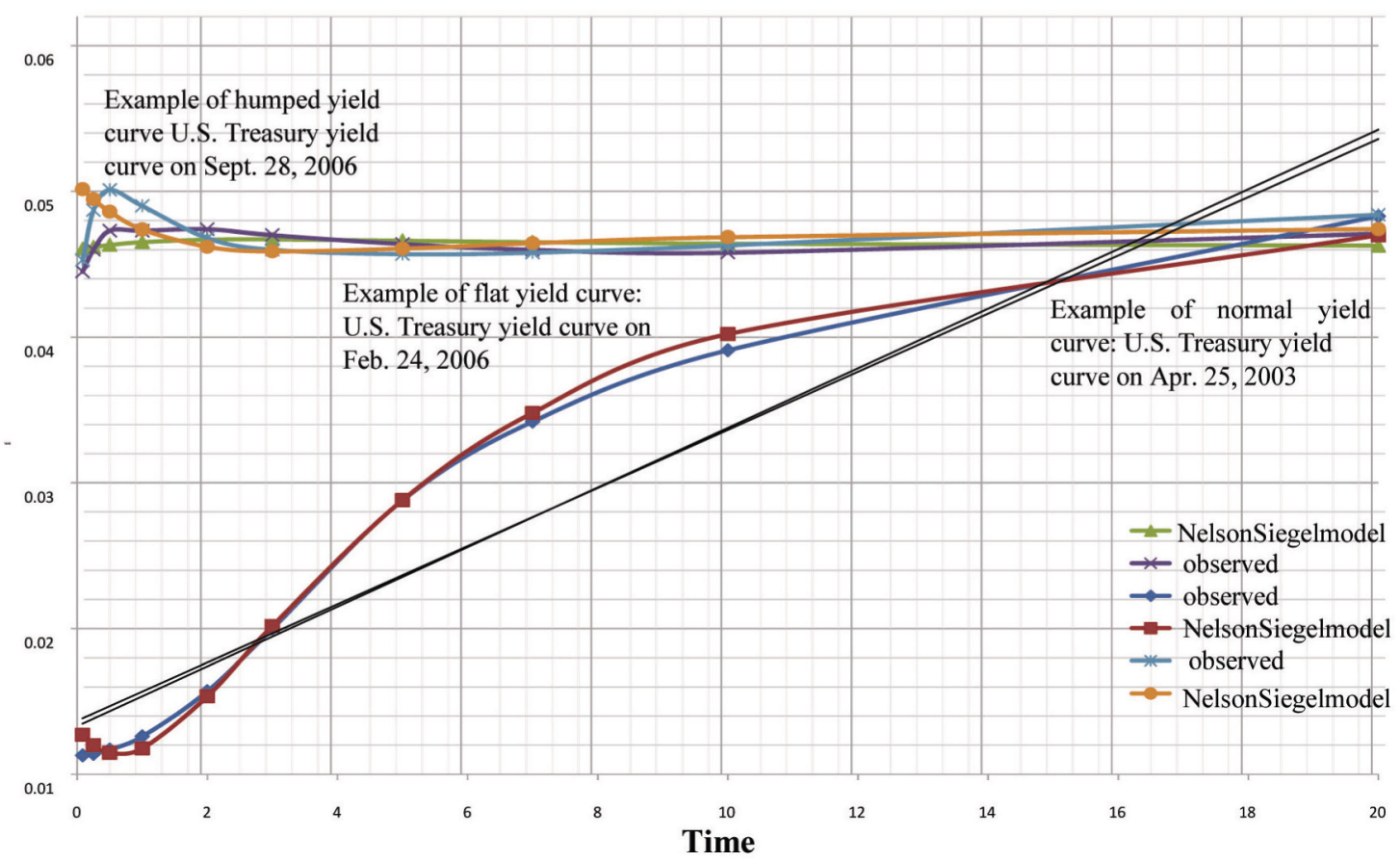

Figure 2. Three U.S. treasury yield curves fitted with Nelson and Siegel (1987) model

Source: the authors

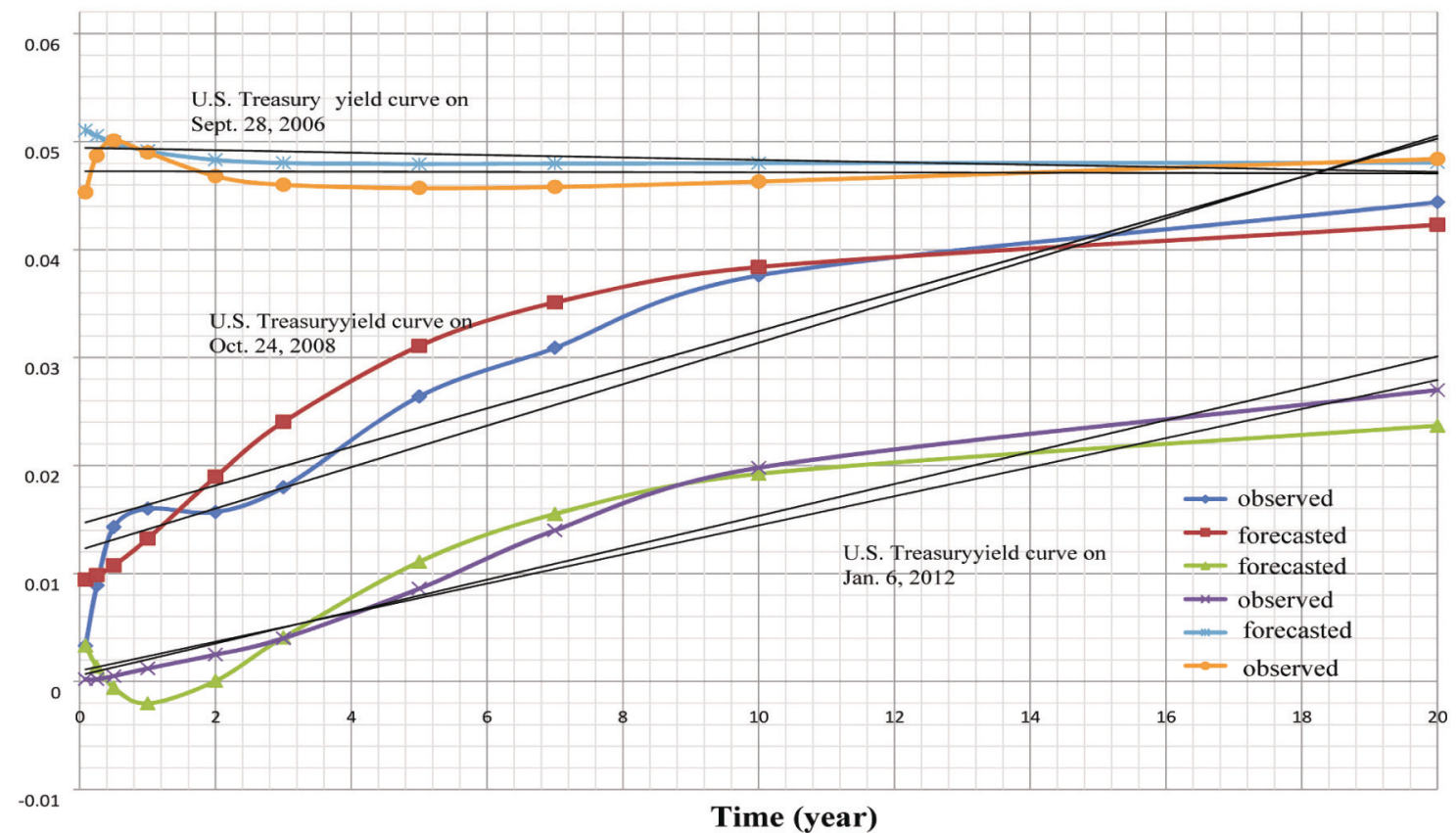

Figure 3. Three U.S. Treasury yield curves forecasted with Diebold and Li (2006) model

Source: the authors 
Figure 3 illustrates three U.S. Treasury yield curves forecasted with the Diebold and Li (2006) model. It emphasizes the limitations of the model when, from top to bottom:

- The observed yield curve is humped such as on September 28, 2006. The Diebold and Li forecasting model does not replicate the hump, with a forecasted curve that simply starts in line with the highest point of the hump then decreases.

- The financial environment is volatile. In 2008, in the turmoil of the credit crisis, we observed much volatility and discrepancies in the market; for example, on October 24, 2008, the VIX index reached an historical high of 89.53 for a long-term average of 19 . This very day, we could observe an irregular yield curve. The forecasted yield curve smoothed the irregularities of the observed yield curve.

- The interest rates are close to zero: during a zero interest rate policy environment imposed by the Federal Reserve, such as on January 6, 2012, the short end of the yield curve forecasted with Diebold and Li (2006) model returns negative nominal rates, which is impossible.

\subsection{The "Stock Dog" Technique}

We couple the "stock dog" technique to the MC simulation of CIR (1985) model. As presented above, CIR proposed to capture the behaviour of the short-term interest rate with the process $d r=\alpha(\mu-r) d t+\sigma \sqrt{\mathrm{r}} d z_{t}$ with $d z_{1}=\varepsilon \sqrt{d t}$.

Step 1: We calibrate equation 2 in order to fit the daily observed yield curve, i.e. to find parameters $\alpha, \mu$ and $\sigma$ corresponding to the maximization of the log-likelihood function (equation 7). We apply Kladivko's (2007) methodology. The log-likelihood function of the CIR process is:

$$
\ln L(\theta)=(N-1) \ln c+\sum_{i=1}^{N-1}\left\{u_{t_{i}}+v_{t_{i}+1}+0.5 q \ln \left(\frac{v_{t_{i+1}}}{u_{t_{i}}}\right)+\ln \left\{I_{q}\left(2 \sqrt{u_{t_{i}} v_{t_{i+1}}}\right)\right\}\right\}
$$

where $u_{t_{i}}=c r_{t_{i}} e^{-\alpha \Delta t}$ and $v_{t_{i+1}}=c r_{t_{i}+1}$. We find maximum likelihood estimates $\theta$ of parameter vector $\theta$ by maximizing the log-likelihood function 7 over its parameter space:

$$
\theta \equiv(\widehat{\alpha}, \widehat{\mu}, \hat{\sigma})=\arg \max _{\theta} \ln L(\theta)
$$

Since the logarithmic function is monotonically increasing, maximizing the log-likelihood function also maximizes the likelihood function. Refer to Kladivko's (2007) methodology, for the practical implementation of the calibration. In order to maximize the log-likelihood function, we need to fit the daily observed yield curve of ten data with a fifth-order polynomial fitting since we need a constant time step during the optimization procedure. Equation 9 illustrates the model:

$$
r_{t}=p_{1} t^{5}+p_{2} t^{4}+p_{3} t^{3}+p_{4} t^{2}+p_{5} t^{1}+p_{6}
$$

with $p_{1}, p_{2}, p_{3}, p_{4}, p_{5}, p_{6}$ the fifth-order polynomial coefficients that fit the observed yield curve in a least-squares sense.

Step 2: We produce yield forecasts based on an underlying univariate AR(1) specification, as:

$$
d r_{t+h / t}=\alpha_{t+h / t}\left(\mu_{t+h / t}-r\right) d t+\sigma_{t+h / t} \sqrt{r} d z_{1}
$$

where:

$$
\begin{aligned}
\alpha_{t+h / t} & =C_{1}+\omega_{1} \alpha_{t}(11) \\
\mu_{t+h / t} & =C_{2}+\omega_{2} \mu_{t}(12) \\
\sigma_{t+h / t} & =C_{3}+\omega_{3} \sigma_{t}(13)
\end{aligned}
$$

$C_{i}$ and $\omega_{i}$ are obtained by regressing $\alpha_{t}$ on an intercept and $\alpha_{t-h}, \mu_{t}$ on an intercept and $\mu_{t-h}$, and finally $\sigma_{t}$ on an intercept and $\sigma_{\mathrm{t}-\mathrm{h}}$. The forecasting horizon is $h=20$ days. We regress the first set of $\alpha, \mu, \sigma$ from 1 to 250 days with the set of $250 \alpha, \mu, \sigma$ obtained between 20 and 270 days, then moving forward one-day at a time. The resulting $\alpha, \mu, \sigma$ are then plugged in equation 10 in order to compute the forecasted yield curve in 20 days.

Step 3: We build bands using the information embedded in the shapes of the most 20 recent yield curves. These bands are built to reflect the intrinsic dynamic forces of the interest rate market that is responsible of the future shape of the term structure. One of our challenges was to identify these forces and to materialize them in bands 
beyond which the future term structure is unlikely to be. The choice of the bands is based on the assumption that the current dynamic forces of the interest rate market are captured by the level $\beta_{l t}$, the slope $\beta_{2 t}$ and the curvature $\beta_{3 t}$ provided by the Nelson and Siegel model from the 20 most recent daily fitted U.S. Treasury yield curves. Therefore, the future yield curve shape in 20 days depends partly on the shapes of the most recent yield curves. Market news occurring in the next 20 days will bring the final touch to the shape. The choice of the 20 past days is conditional to the forecasting horizon of 20 days and should be adjusted to the forecasting horizon. We pick $\beta_{1 t}$ $\beta_{2 t}, \beta_{3 t}$ independently among the 20 most recent days such as that, based on equation 4 , their combination maximizes $\Sigma y_{t}(\tau)$ to obtain the upper band and minimizes $\Sigma y_{t}(\tau)$ to obtain the lower band. The loadings (i.e. coefficients) of $\beta_{1 t}, \beta_{2 t}, \beta_{3 t}$ are a function of time and are graphed in figure 4 .

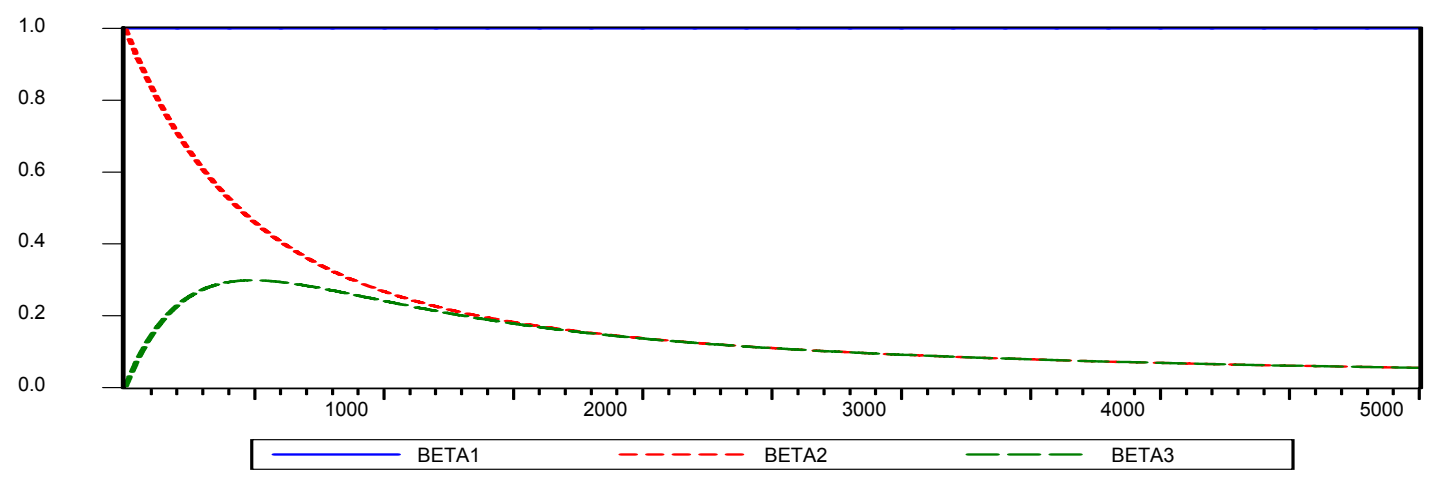

Figure 4. Factor loadings of Nelson and Siegel (1987) model for Lambda $=0.91$

Source: the authors

From equation 4 , the loading of $\beta_{1 t}$ is equal to the constant 1 , the loading of $\beta_{2 t}$ is $\left(1-e^{-\lambda \tau} t\right) /\left(\lambda_{t} \tau\right)$ and the loading of $\beta_{3 t}$ is $\left\{\left(1-e^{-\lambda \tau}\right) /\left(\lambda_{t} \tau\right)-e_{t}^{-\lambda \tau}\right\}$. The corresponding function of $\beta_{2 t}$ loading starting at 1 decreases gradually overtime. The corresponding function of $\beta_{3 t}$ loading starts at time zero, then increases to reach a maximum at 1.97 year (when $\lambda$ is set at 0.91 ), and finally decreases steadily. We find estimates $\theta$ of parameter vector $\theta$ by optimizing equations 14 and 15 over their parameter spaces:

$$
\theta \equiv\left(\widehat{\beta_{1 t}}, \widehat{\beta_{2 t}}, \widehat{\beta_{3 t}}\right)=\arg \max _{\theta} \sum_{i=1}^{10} y_{i}(\tau)(\theta)
$$

Equation 14 is used to obtain the upper band.

$$
\theta \equiv\left(\widehat{\beta_{1 t}}, \widehat{\beta_{2 t}}, \widehat{\beta_{3 t}}\right)=\arg \min _{\theta} \sum_{i=1}^{10} y_{i}(\tau)(\theta)
$$

Equation 15 is used to obtain the lower band.

with $\operatorname{Min}\left(B_{i, t-20: t}\right)<\left(\widehat{\beta_{i t}}\right)<\operatorname{Max}\left(B_{i, t-20: t}\right)_{i=1,2,3}$.

And $y_{i}(\tau)$ obtained from equation 4 .

The intuition behind the bands is that, in the last 20 days, the more volatile the interest rate market was, the wider the range of $\beta_{i}$ values was, the wider the bands will be. With a volatile market, the shape of the yield curve in 20 days is more likely to be different from the ones of the most recent yield curves, since the number of possible combinations of $\beta_{1 t}, \beta_{2 t}, \beta_{3 t}$ increases. Inversely, with a low-volatility market, the narrower the range of $\beta_{i}$ values was, the tighter the bands will be. With a limited number of combinations of $\beta_{i}$, the shape of the yield curve in 20 days is more likely to look the same as the most recent shapes. Therefore, the bands provided by the "stock dog" technique behave very much like Bollinger bands to reflect the volatility of the market (refer to Théoret et al., 2006) but capture additional information related to the shape of the future yield curve. In conclusion, the upper and lower bands are reasonable limits constructed on intrinsic information obtained from the shapes of the 20 most recent yield curves, beyond which the current market forces make the 20-day forecasted yield curve unlikely to be.

Step 4: We simulate equation 10 ten times using MC simulation and the "stock dog" technique. The latter 
algorithm, acting as a stock or herding dog, makes sure that the simulated interest rate does not go beyond the upper and lower bands but stay inside the interval. As soon as the upper or lower bands are crossed, the algorithm throws back the interest rate in the middle of the bands. The initial value of the simulated yield curve (maturity $\mathrm{T}=0$ ) is the 1-month interest rate that we read on the yield curve 20 days backward. Finally, we compute the average yield curve of the ten simulated curves, which is the forecasted 20-day yield curve obtained with the "stock dog" technique. We compare it to the observed yield curve applying the RMSE criteria (equation 21).

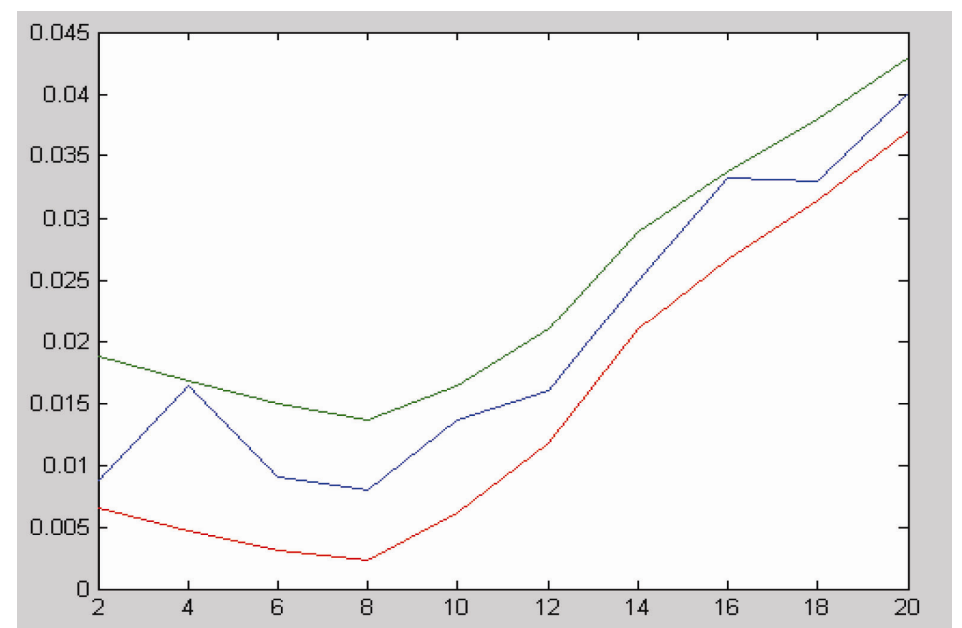

Figure 5. One Monte Carlo simulation of the 20-day forecasted yield curve of July 31, 2003 using the CIR (1985) model and the "stock dog" technique with upper and lower bands

Source: the authors

Figure 5 illustrates one MC simulation of the 20-day forecasted yield curve for July 31, 2003 using the CIR (1985) model and the "stock dog" technique with upper and lower bands.

\subsection{Stochastic Fifth-Order Polynomial Model}

Our paper also features a stochastic fifth-order polynomial model to capture the yield curve. Equation 16 proposed by Rostan and Rostan (2012) illustrates the model:

$$
r_{t}=p_{1} t^{5}+p_{2} t^{4}+p_{3} t^{3}+p_{4} t^{2}+p_{5} t^{1}+p_{6}+\sqrt{\tilde{r}_{t}} \cdot \tilde{\sigma} \cdot \varepsilon
$$

with $p_{1}, p_{2}, p_{3}, p_{4}, p_{5}, p_{6}$ the fifth-order polynomial coefficients that fit the observed yield curve in a least-squares sense; $\tilde{r}_{t}$ is the fifth-order polynomial interest rate estimate at time $t$.

Equation 18 models the trend -the drift function- with the fifth-order polynomial fitting of the yield curve. The annualized volatility of the short-term interest-rate $(\tilde{\sigma})$ is obtained using equation 17 :

$$
\tilde{\sigma}=\sqrt{\frac{1}{N} \sum_{t=1}^{N}\left(r_{t}-\tilde{r}_{t}\right)^{2}} \cdot \sqrt{252}
$$

With $\tilde{r}_{t}$ the fifth-order polynomial interest rate estimate at time $t$ and $r_{t}$ the rate at time $t$ of the observed yield curve.

Step 1: We calibrate equation 16 by computing the polynomial coefficients of equation 9 and the volatility with equation 17.

Step 2: We produce forecasts of the fifth-order polynomial coefficients and the volatility based on an underlying univariate $\mathrm{AR}(1)$ specification, as:

$$
r_{t+h / t}=p_{1, t+h / t} t^{5}+p_{2, t+h / t} t^{4}+p_{3, t+h / t} t^{3}+p_{4, t+h / t} t^{2}+p_{5, t+h / t} t^{1}+p_{6, t+h / t}+\sqrt{\tilde{r}_{t}} \cdot \widetilde{\sigma_{t+h / t}} \cdot \varepsilon
$$


where:

$$
\begin{aligned}
p_{i, t+h / t} & =C_{i}+\omega_{i} p_{i t} \\
\widetilde{\sigma_{t+h / t}} & =C_{i}+\omega_{i} \widetilde{\sigma}_{t}
\end{aligned}
$$

Step 3: We simulate equation 18 ten times using MC simulation and the "stock dog" technique. The average yield curve of the ten simulated curves is the forecasted 20-day yield curve.

\subsection{Root Mean Square Error (RMSE)}

Each of the three models listed above provides 2,321 20-day forecasts of the yield curves from September 27, 2002 to January 6,2012 . We compare the forecasts to the observed yield curves by computing the RMSE:

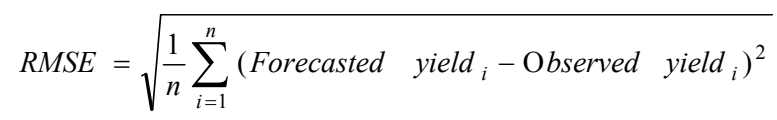

\subsection{Database}

The database includes market yields of U.S. Treasury securities (bills and notes) at 1-, 3-, 6-month, 1-, 2-, 3-, 5-, 7-, 10- and 20-year constant maturity, quoted on investment basis yields on actively traded non-inflation-indexed issues adjusted to constant maturities. The U.S. yield curves extend from July 31, 2001 to January 6, 2012 or 2,611 days and are obtained from the Federal Reserve website [1]. We forecast 2,321 U.S. yield curves from September 27, 2002 to January 6, 2012. Since the 30-year Treasury constant maturity series was discontinued on February 18, 2002, and reintroduced on February 9, 2006, we discard the 30-year maturity.

\section{Results}

Applying the RMSE criteria (equation 21) to Diebold \& Li (2006) model and the "stock dog" techniques to an out-of-sample of 2,321 20-day forecasted yield curves from September 27, 2002 to January 6, 2012, we obtain table 1 .

Table 1. Computing the average RMSE over 2,321 days for the Diebold and Li model (2006), the CIR (1985)

\begin{tabular}{|c|c|c|c|}
\hline & $\begin{array}{l}\text { 20-day forecasted } \\
\text { yield curves with } \\
\text { Diebold and Li } \\
\text { model (2006) versus } \\
\begin{array}{l}\text { observed yield } \\
\text { curves }\end{array} \\
\end{array}$ & $\begin{array}{l}\text { 20-day forecasted yield } \\
\text { curves with the "stock } \\
\text { dog" technique and the } \\
\text { CIR model (1985) } \\
\text { versus observed yield } \\
\text { curves }\end{array}$ & $\begin{array}{l}\text { 20-day forecasted yield } \\
\text { curves with the "stock dog" } \\
\text { technique and the Stochastic } \\
\text { Fifth-Order Polynomial } \\
\text { model (2012) versus } \\
\text { observed yield curves }\end{array}$ \\
\hline $\begin{array}{l}\text { Average RMSE of } 2,321 \\
\text { forecasted yields curves }\end{array}$ & 0.003099582 & 0.002968451 & 0.003060926 \\
\hline
\end{tabular}
model and the Stochastic Fifth-Order Polynomial (2012) model

Table 1 shows the significant advantage of the stock dog technique. The Test for Equality of Means Between Series in Table 2 confirms that the RMSE averages of the three models are statistically different (i.e. Anova F-statistic $p$-value less than 5\%), the CIR (1985) model being the best predictor followed by the Stochastic Fifth-Order Polynomial (2012) model and Diebold and Li (2006) model.

Table 2. Test for equality of means between series of the average RMSE over 2,321 days for the Diebold and Li (2006) model, the CIR (1985) model and the Stochastic Fifth-Order Polynomial (2012) model

\begin{tabular}{lrrr}
\hline Test for Equality of Means Between Series - Sample: 1 & 2321 Included observations: 2321 \\
\hline Method & $\mathrm{df}$ & Value & Probability \\
Anova F-statistic & $(2,6960)$ & 3.219515 & 0.0400 \\
Analysis of Variance & $\mathrm{df}$ & Sum of Sq. & Mean Sq. \\
Source of Variation & & & \\
Between & 2 & $2.11 \mathrm{E}-05$ & $1.05 \mathrm{E}-05$ \\
Within & 6960 & 0.022781 & $3.27 \mathrm{E}-06$ \\
Total & 6962 & 0.022802 & $3.28 \mathrm{E}-06$ \\
\hline
\end{tabular}




\begin{tabular}{crrrr}
\hline Variable & Count & Mean & Std. Dev. & Std. Err.of Mean \\
RMSE-Diebold and Li & 2321 & 0.003100 & 0.002099 & $4.36 \mathrm{E}-05$ \\
RMSE-CIR & 2321 & 0.002968 & 0.001663 & $3.45 \mathrm{E}-05$ \\
RMSE-Polynomial & 2321 & 0.003061 & 0.001628 & $3.38 \mathrm{E}-05$ \\
All & 6963 & 0.003043 & 0.001810 & $2.17 \mathrm{E}-05$ \\
\hline
\end{tabular}

Figure 6 brings a better understanding of the behaviour of the RMSE overtime.

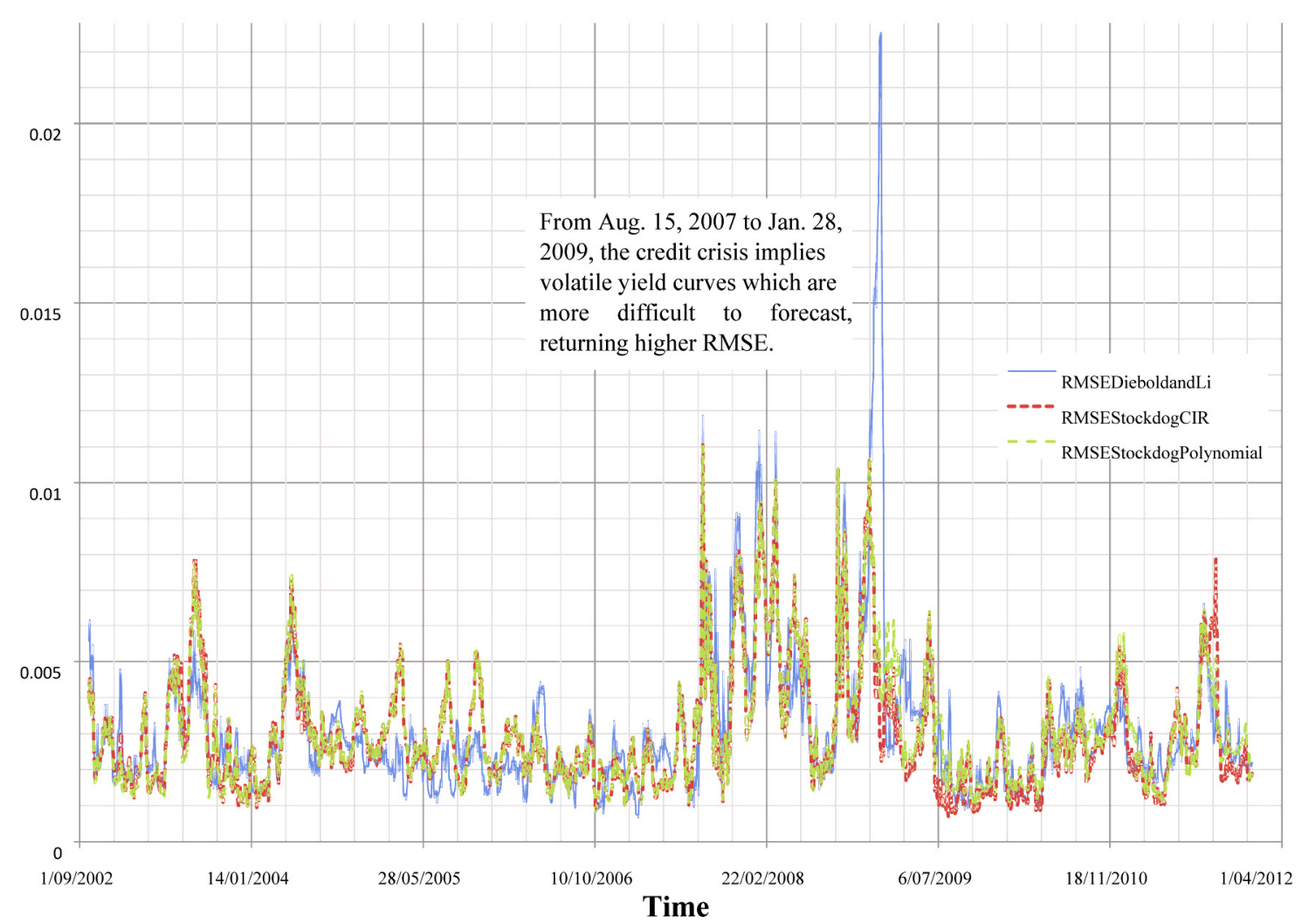

Figure 6. Computing the daily RMSE over 2,321 days for the Diebold and Li (2006) model, the CIR (1985) model and the Stochastic Fifth-Order Polynomial (2012) model

Source: the authors

Figure 6 highlights the fact that during volatile periods, the forecasting power of all models decreases. The credit crisis extended from mid-2007 to the beginning of 2009 and brought volatility and anomalies in the yield curves, which are more challenging to forecast. For example, figure 3 shows a particular day, Oct. 24, 2008, where the VIX index was at a historical high. The shape of the U.S. Treasury yield curve was shaky and irregular. Finally, Figure 6 shows that, except during the credit crisis period where the Diebold and Li (2006) model is particularly inefficient, all three models follow similar patterns of high and low forecasting power over the period.

\section{Discussion}

We designed an innovative technique coupled with MC simulation that accurately forecast the yield curve. This "stock dog" technique forces the simulated yield curve inside bands, using the information embedded in the shapes of the most recent yield curves. These bands are built to reflect the intrinsic dynamic forces of the current interest rate market environment responsible of the future shape of the yield curve. We assume that these forces are captured by the level, the slope and the curvature $\beta_{1 t}, \beta_{2 t}, \beta_{3 t}$ provided by the Nelson and Siegel (1987) model from the most recent daily fitted yield curves. Thus, the future yield curve shape depends partly on the shapes of the most recent yield curves and partly on the news happening during the forecasting period. Based on the RMSE criteria, the "stock dog" technique coupled either with the CIR (1985) or the Stochastic Fifth-Order 
Polynomial models is superior to the Diebold and Li (2006) model for forecasting yield curves in 20 days. Further works on the topic could test the "stock dog" technique coupled to 2-factor models such as Fong and Vasicek (1992) model.Factor-augmented vector autoregression models that are much in fashion nowadays could also be benchmarked to our "stock dog" technique. Finally, longer-term forecasting horizon may be tested.

\section{Acknowledgements}

The authors express gratitude to Professor Wanncherng Wang, National Sun-Yat University, Taiwan, and Mr. Dang-Thanh Ngo, VNU University of Economics and Business, Vietnam, for their observations and comments at the $6^{\text {th }}$ Asian Business Research Conference, Bangkok, 2012.

\section{References}

Audrino, F., \& Trojani, F. (2007). Accurate Short-Term Yield Curve Forecasting using Functional Gradient Descent. Journal of Financial Econometrics, 5(4), 591-623. http://dx.doi.org/10.1093/jjfinec/nbm011

Almeida, C. R., Duarte, A. M., \& Fernandes, C. C. (1998). Decomposing and simulating the movements of term structures of interest rates in emerging Eurobond markets. Journal of Fixed Income, 8(1), 21-31. http://dx.doi.org/10.3905/jfi.1998.408229

Andersen, A., Lundb, J., \& Torben, G. (1997). Estimating continuous-time stochastic volatility models of the $\begin{array}{llllll}\text { short-term interest rate. Journal of Econometrics, } & 77, & 343-377 .\end{array}$ http://dx.doi.org/10.1016/S0304-4076(96)01819-2

Bali, T. G., \& Wu, L. (2006). A comprehensive analysis of the short-term interest-rate dynamics? Journal of Banking \& Finance, 30(2), 1269-1290. http://dx.doi.org/10.1016/j.jbankfin.2005.05.003

Bernadell, C., Coche, J., \& Nyholm, K. (2005). Yield curve prediction for the strategic investor. working paper no. 472, European Central Bank.

Bing-Huei, L. (1999). Fitting the term structure of interest rates for Taiwanese government bonds. Journal of Multinational Financial Management, 9(2), 149-161.

Bliss, R. (1997). Movements in the term structure of interest rates. Economic Review, Federal Reserve Bank of Atlanta, 4, 16-33.

Chen, R., \& Scott, L. (1993). Maximum Likelihood Estimation for a Multifactor Equilibrium Model of the Term Structure Of Interest Rates. Journal of Fixed Income, 4, 14-31. http://dx.doi.org/10.3905/jfi.1993.408090

Clinton, K. (1995). The term structure of interest rates as a leading indicator of economic activity: a technical note. Bank of Canada Review, 23-40.

Cox, J. C., Ingersoll, J. E., \& Ross, S. A. (1985). The theory of the term structure of interest rates. Econometrica, 539(2), 363-384. http://dx.doi.org/10.2307/1911241

Delbaen, F., \& Shirakawa, H. (2002). An interest rate model with upper and lower bounds. Asia-Pacific Financial Markets, Dordrecht, 9, 191-209. http://dx.doi.org/10.1023/A:1024125430287

Day, J., \& Lange, R. (1997). The Structure of Interest Rates in Canada: Information Content about Medium-Term Inflation. Working paper no.97-10, Bank of Canada.

Dai, Q., \& Singleton, K. (2000). Specification Analysis of Affine Term Structure Models. Journal of Finance, 55, 1943-1978. http://dx.doi.org/10.1111/0022-1082.00278

De Jong, F. (2000). Time Series and Cross-Section Information in Affine Term-Structure Models. Journal of Business \& Economic Statistics, 18(3), 300-314. http://dx.doi.org/10.2307/1392263

Diebold, F., \& Li, C. (2003). Forecasting the Term Structure of Government Bond Yields. working paper no.10048, National Bureau of Economic Research.

Diebold, F., \& Li, C. (2006). Forecasting the Term Structure of Government Bond Yields. Journal of Econometric, 130, 337-364. http://dx.doi.org/10.1016/j.jeconom.2005.03.005

Dolan, C. (1999). Forecasting the yield curve shape: evidence from global markets. The Journal of Fixed Income, 10, 40-53. http://dx.doi.org/10.3905/jfi.2005.523089

Duffee, G. (2002). Term Premia and Interest Rate Forecasts in Affine Models. The Journal of Finance, 57, 405-443. http://dx.doi.org/10.1111/1540-6261.00426

Fabozzi, J., Martellini, L., \& Priaulet, P. (2005). Predictability in the shape of the term structure of interest rates. 
The Journal of Fixed Income, 15, 40-53.

Fong, H. G., \& Vasicek, O. A. (1992). Interest Rate Volatility as a Stochastic Factor. Working paper, Gifford Fong Associates.

Füss, R., \& Nikitina, O. (2011). Explaining Yield Curve Dynamics. The Journal of Fixed Income, 21 , 68-87. http://dx.doi.org/10.3905/jfi.2011.21.2.068

Hong, Y. (2001). Dynamic Models of the Term Structure. Financial Analysts Journal, 57, 60-76. http://dx.doi.org/10.2469/faj.v57.n4.2466

Kladivko, K. (2007). Maximum likelihood estimation of the Cox-Ingersoll-Ross process: the Matlab implementation. Working paper, Department of Statistics and Probability Calculus, University of Economics, Prague and Debt Management Department, Ministry of Finance of the Czech Republic.

Kornbluth, J. S., Salkin, H., \& Omega, G. R. (1992). Polynomial yield curve models for Tilting Portfolios. Oxford, 20, 241.

Leite, A. L., Filho, R. B. P. G., \& Vicente, J. V. M. (2010). Forecasting the yield curve: a statistical model with market survey data. International Review of Financial Analysis, 19, 108. http://dx.doi.org/10.1016/j.irfa.2010.02.001

Litterman, R., \& Scheinkman, J. (1991). Common Factors Affecting Bond Returns. Journal of Fixed Income, 1, 54-61. http://dx.doi.org/10.3905/jfi.1991.692347

Lund, J., \& Christiansen, C. (2005). Revisiting the Shape of the Yield Curve: The Effect of Interest Rate Volatility. Working paper, Aarhus School of Business.

McCulloch, J. H. (1971). Measuring the Term Structure of Interest Rates. Journal of Business, 44, 19-31. http://dx.doi.org/10.1086/295329

McCulloch, J. H. (1975). The tax adjusted yield curve. Journal of Finance, 30, 811-830.

Nelson, C. R., \& Siegel, A. F. (1987). Parsimonious Modeling of Yield Curves. Journal of Business, 60, $473-489$. http://dx.doi.org/10.1086/296409

Pham, T. M. (1998). Estimation of the term structure of interest rates: an international perspective. Journal of Multinational Financial Management, 8, 265-283. http://dx.doi.org/10.1016/S1042-444X(98)00031-0

Rebonato, R. (1996). Interest-rate option models. Hoboken, New Jersey: John Wiley \& Sons.

Rostan, P., \& Rostan A. (2012). Testing an innovative variance reduction technique for pricing bond options in the framework of Cox Ingersoll Ross model. Aestimatio, The IEB International Journal of Finance, 4, 2-19.

Shea, G. (1984). Pitfalls in smoothing interest rate term structure data: Equilibrium models and spline approximations. Journal of Financial and Quantitative Analysis, 19, 253-269. http://dx.doi.org/10.2307/2331089

Shea, G. (1985). Interest rate term structure estimation with exponential splines: A note. Journal of Finance, 11, 319-325.

Svensson, L. E. O. (1995). Estimating forward interest rates with the extended Nelson and Siegel method. SverigesRiskbank Quarterly Review, 3, 13-26.

Théoret, R., Rostan, P., \& El Moussadek, A. (2005). Forecasting the Interest-rate Term Structure: Using the Model of Fong and Vasicek, the Extended Kalman Filter and the Bollinger Bands. Working paper, SSRN.

Théoret, R., Rostan, P., \& El Moussadek, A. (2006). An essay on stochastic volatility and the yield curve. In Gregoriou, G. (Ed.), Advances in Risk Management. London: Palgrave-MacMillan, 251-274.

Vasicek, O. A. (1977). An equilibrium characterization of the term structure. Journal of Financial Economics, 5, 177-188. http://dx.doi.org/10.1016/0304-405X(77)90016-2

Vasicek, O. A., \& Fong, H. G. (1982). Term Structure Modeling Using Exponential Splines. Journal of Finance, 37(2), 339-348.

Vicente, J., \& Tabak, B. (2008). Forecasting bond yields in the Brazilian fixed income market. International Journal of Forecasting, 24, 490. http://dx.doi.org/10.1016/j.ijforecast.2008.03.009

Zantedeschi, D., Damien, P., \& Polson N. G. (2011). Predictive Macro-Finance with Dynamic Partition Models. Journal of the American Statistical Association, 106, 427-439. http://dx.doi.org/10.1198/jasa.2011.ap09732 


\section{Note}

Note 1. Retrieved from the Federal Reserve website: http://www.federalreserve.gov/releases/h15/data.htm Accessed on 10 January 2012. 